\title{
Diretrizes para o planejamento ambiental e análise diagnóstica das interações entre recurso hídrico e urbanização, com o uso de geoprocessamento.
}

Guidelines for environmental planning and diagnostic analysis of the interactions between water resources and urbanization, using geoprocessing.

Directrices para la planificación ambiental y el análisis de diagnóstico de las interacciones entre los recursos hídricos y la urbanización, utilizando el geoprocesamiento.

\section{Rodrigo Guimarães Pinho}

Mestre em Geografia - UFMS/CPTL. Especialista em Docência e Gestão do Ensino Superior pela Universidade do Oeste Paulista (2016). Graduado em Arquitetura e Urbanismo pela Universidade Metodista de Piracicaba (2006). Pesquisador no grupo: Diretrizes de Gestão Ambiental com Uso de Geotecnologias. Universidade Federal do Mato grosso do Sul - CPTL, Brasil. arq.rodrigo.pinho@hotmail.com

\section{Patrícia Helena Mirandola Garcia}

Doutora e Docente do Programa de Pós-Graduação em Geografia Mestrado e Doutorado (UFMS/Três Lagoas) e do Programa de Pós Graduação Stricto Sensu em Ensino de Ciências (Doutorado) - Área Educação Ambiental, do Instituto de Física da Fundação Universidade Federal de Mato Grosso do Sul (UFMS-Campo Grande). Universidade Federal do Mato grosso do Sul - CPTL, Brasil. patriciaufmsgeografia@gmail.com

\section{Marcelo Suveges Garcia}

Mestre em Geografia - UFMS/CPTL. Graduado em Geografia (Bacharelado e Licenciatura) pela Universidade Estadual Paulista "Júlio de Mesquita Filho" - campus de Presidente Prudente (2016). Universidade Federal do Mato grosso do Sul - CPTL, Brasil. marcelo_geo@live.com 
RESUMO: O presente trabalho discute as interações entre os recursos naturais e a urbanização. Estabelecido a partir da delimitação da bacia hidrográfica do Córrego da Onça em Três Lagoas/MS-Brasil; busca o entendimento da dinâmica ambiental, levando em consideração as variações dos atributos físicos, bióticos e antrópicos no território. O recorte temporal apresenta dados geográficos e cartográficos de caracterização à análise diagnóstica, para assim, verificar aquilo que está no espaço-tempo do objeto de estudo. Baseia-se numa ação de planejamento ambiental que se inicia pelo diagnóstico preliminar, verificando o uso e cobertura da terra, por meio de geoprocessamento, e o associa à qualidade das águas com vistas a designar possíveis percursos de ação que, ao serem submetidos à leitura e ao debate público, possam desencadear iniciativas de urbanismo prático. Conclui a discussão com a indicação de diretrizes de planejamento que podem gerar as condições para a constituição de outros cenários.

Palavras-chave: Planejamento Ambiental; Bacia Hidrográfica; Geoprocessamento; Uso e Cobertura da Terra.

ABSTRACT: This paper discusses the interactions between natural resources and urbanization. Established from the delimitation of the stream da Once hydrographic basin in Três Lagoas/MS- Brazil; seeks to understand the environmental dynamics, taking into account the variations of the physical, biotic and anthropic attributes in the territory. The temporal clipping presents geographic and cartographic characterization data to the diagnostic analysis, in order to verify what is in the space-time of the object of study It is based on an environmental planning action that begins with the preliminary diagnosis, verifying the use and coverage of the land, through geoprocessing, and associates it with the quality of the waters with a view to designating possible pathways of action that, when subjected to reading and the public debate, can trigger initiatives of practical urbanism. Concludes the discussion with the indication of planning guidelines that can generate the conditions for the constitution of other scenarios.

Keywords: Environmental Planning; Hydrographic basin; Geoprocessing; Use and Coverage of the Earth.

RESUMEN: Este artículo discute las interacciones entre los recursos naturales y la urbanización. Establecido a partir de la delimitación de la cuenca hidrográfica Córrego da Onça en Três Lagoas / MS-Brasil; busca comprender la dinámica ambiental, teniendo en cuenta las variaciones de los atributos físicos, bióticos y antrópicos en el territorio. El marco temporal presenta datos geográficos y cartográficos desde la caracterización hasta el análisis de diagnóstico, con el fin de verificar qué hay en el espacio-tiempo del objeto de estudio. Se basa en una acción de planificación ambiental que comienza con el diagnóstico preliminar, verificando el uso de la tierra y la cobertura, a través del geoprocesamiento, y lo asocia con la calidad del agua para designar posibles cursos de acción que, cuando se someten a lectura y el debate público, puede desencadenar iniciativas prácticas de planificación urbana. Concluye la discusión con la indicación de pautas de planificación que pueden generar las condiciones para la constitución de otros escenarios.

Palabras clave: Planificación ambiental; Cuenca hidrográfica; Geoprocesamiento; Uso del suelo y cobertura. 


\section{INTRODUÇÃO}

No que tange ao campo ambiental, a relação entre os recursos naturais e a urbanização apresenta, ao longo da história, uma interação muitas vezes conflituosa. Até as décadas de $60 \mathrm{e}$ 70 do século $X X$ a sociedade vislumbrava a natureza como fonte inesgotável de recursos, ou ainda em visão mais agressiva: como obstáculo ao desenvolvimento e crescimento econômico dos grupos sociais em detrimento da gradativa consolidação do modo de produção capitalista. Este paradigma colocava a natureza, diante da sociedade, em uma situação de mutua exclusão, uma vez que a tendia a apontar que a "existência de uma significava a destruição, em maior ou menor intensidade da outra" (BORGES, 2003).

Este estudo objetiva compreender as interações entre os recursos naturais e a urbanização, integrados pelos meios urbano e rural, estabelecidos a partir da delimitação da Bacia Hidrográfica do Córrego da Onça (BHCO) no município de Três Lagoas/MS, Brasil; utilizando as geotecnologias, apoiados em uma pesquisa diagnóstica de planejamento ambiental que se inicia pela associação da identificação do uso e cobertura da terra e à qualidade das águas do recurso hídrico, com vistas a apontar possíveis percursos de ação, que ao serem submetidos à leitura e ao debate público possam desencadear iniciativas de urbanismo prático.

Desta maneira, torna-se relevante a busca de um planejamento ambiental tal qual define Franco (2003, p.35) como: "o planejamento que parte do princípio da valoração e conservação das bases naturais de um dado território com base de auto sustentação da vida e das interações que mantém, ou seja, das relações ecossistêmicas".

Nesta perspectiva a adoção de bacias hidrográficas, como recorte de estudo para leitura do território e unidade de planejamento, possibilita uma análise dos componentes naturais e sociais que a constituem de modo sistêmico e relacional; neste contexto espacial é possível definir a bacia hidrográfica, conforme Santos (2004) como:

[...] um sistema natural bem delimitado no espaço, composto por um conjunto de terras topograficamente drenadas por um curso d'água e seus afluentes, onde as interações, pelo menos físicas, são integradas e, assim, mais facilmente interpretadas. (SANTOS, 2004, p.40).

Ao considerar: a presença da urbanização no recorte da bacia hidrográfica e evidenciando-se a necessidade de intervenções urbanísticas, se torna relevante dedicar à ação pautada no direcionamento de um urbanismo prático conduzido por um debate público não apenas sobre um projeto e sim um debate público para um projeto; caracterizando um processo dinâmico de modo a provocar um movimento solenoidal que envolve: debate, confronto, negociação, consenso e compromisso, a fim de formar o solenoide que segundo Pereira (2008):

[...] é formado pelo enrolar de um fio em espiral regular ao redor de um eixo fictício e cada volta da espira permite definir melhor este eixo e seu ângulo de visão. O projeto a ser elaborado corresponderia de algum modo a este eixo de solenoide e o debate público às voltas de espira sucessivas que progressivamente definem o eixo indeterminado no início. (PEREIRA, 2008, p.33) 
Para alcançar um princípio de ação organizadora que não manipule e sim comunique, dirigida por meio do ânimo coletivo e aplicando sistematicamente o conhecimento para avaliar percursos com vistas à tomada de decisão adequada e racional que sirva de fundamentação para ações no presente e no futuro. Sendo que um dos primeiros passos consiste em pesquisar e identificar os principais fatores que afetam uma situação, e com base nesse conhecimento propor sua reorganização.

Este passo pode ser elaborado por meio de um diagnóstico que deverá apresentar uma "fotografia" da realidade a ser analisada a fim de estabelecer uma situação dada.

Dentro de uma perspectiva diagnóstica da interação entre os recursos naturais e a urbanização, realizada a partir da delimitação da bacia hidrográfica, pode-se notar o conflito entre grupos sociais, o meio ambiente, a municipalidade e o Direito. Ocupações irregulares, ora em estado de consolidação, ora consolidadas historicamente, sobrepõem-se as faixas que deveriam ser preservadas de acordo com a legislação ambiental.

Em ambos os casos é necessário estabelecer modos de tratamento adequados as Áreas de Preservação Permanentes (APP's), uma vez que estas possuem uma importância impar na conservação da biodiversidade, bem como se apresentam como mecanismos relevantes na melhoria da qualidade do ar e na regulação térmica e ainda possibilitam o monitoramento de casos de alagamento em áreas urbanas.

A análise de variáveis ambientais se faz em uma escala de grandeza variada, identificando as mudanças catastróficas ou graduais, perceptíveis no espaço (BERGER, 1996 citado por COLTRINARI 2001). Os estudos referentes a tais variáveis foram bastante desenvolvidos em setores específicos, como: na biologia, referindo-se a espécies indicadoras de qualidade ambiental; na economia a definição de variáveis é efetivamente aplicada na determinação de índices de desenvolvimento; nas questões ambientais, podemos apontar as variáveis de qualidade da água e ainda qualidade térmica a partir da cobertura vegetal.

Para chegar a uma interpretação de caráter sistêmica, considerada a partir das idealizações de Ludwig Von Bertalanffy sobre a Teoria Geral dos Sistemas é necessário a realização de estudos de análise ambiental, por meio das transformações possíveis em função de projetos de uso da terra, nas suas diversas categorias, é exigência que se encaixa como medida preliminar em face da política de desenvolvimento sustentável (CHRISTOFOLETTI, 1999).

\section{METODOLOGIA}

O trabalho operacional da pesquisa foi norteado pela organização em três etapas: levantamento dos dados e elaboração de informações, análise diagnóstica a partir da atualidade observada e a estruturação de proposições.

$\mathrm{Na}$ etapa do levantamento de dados foi executada pesquisa de referencial teórico em artigos, científicos, livros, dissertações e teses, bem como foram efetuadas buscas em sites de órgãos de pesquisa renomados e confiáveis.

Realizou-se a captação de dados de ferramentas de sensoriamento remoto: dados orbitais Landsat 8 OLI (Operational Land Image) 2016, além disso, coletaram-se dados SRTM (Shuttle 
Radar Topography Mission) do ano de 2000 obtidos junto ao site da USGS. Estes e outros dados estruturaram o Banco de Dados Geoambiental, passo fundamental para o inicio do projeto BHCO - Córrego da Onça.

O processamento dos dados orbitais foi realizado em Sistema de Informações Geográficas (SIG) mediante o uso do software SPRING ${ }^{\circledR}$ 5.4.2 (desenvolvido pelo INPE) tendo o Datum Sirgas 2000 e projeção Polyconic, utilizando-se o modelo RGB, sobrepondo às bandas 7,6 e 4 da cena 223/74 (órbita/ponto), com os seguintes procedimentos operacionais: criação do banco de dados geográfico; caracterização do projeto, por meio da criação de categorias de dados e planos de informação; importação dos dados orbitais; realce e contraste (equalização do histograma) e classificação supervisionada para elaboração dos mapas de uso e cobertura da terra. Também utilizou-se o software Global Mapper 16 para processar a imagem SRTM a fim de extrair a delimitação da bacia hidrográfica a partir do Modelo Numérico de Terreno (MNT).

O mapa temático de uso e cobertura da terra foi elaborado por meio de classificação a partir da segmentação por regiões e a legenda segue a paleta de cores extraída do Manual Técnico de Uso da Terra (IBGE 2016).

As informações levantadas via satélite foram ratificadas por verificação teórica, conduzida através de consultas aos endereços eletrônicos de instituições reconhecidas, tais como: Instituto Brasileiro de Geografia e Estatística (IBGE), Instituto Nacional de Pesquisas Espaciais (INPE) e banco de teses da Universidade Federal de Mato Grosso do Sul (UFMS) captando informações e referencial teórico; além do aprofundamento na bibliografia indicada; de onde foram extraídos materiais quantitativos e qualitativos.

A finalização da montagem do material gráfico foi efetuada no editor gráfico Corel Draw ${ }^{\circledR}$ X5 e a editoração de textos, gráficos e tabelas mediante o uso do Pacote Office ${ }^{\circledR} 2010$.

A segunda etapa constituiu-se na análise diagnóstica, apresentada na discussão das informações espaciais geradas a partir dos dados primários, bem como de sua relação com dados textuais e alfanuméricos levantados no referencial teórico promovendo uma ação reflexiva com base na categoria de análise do território; com vistas a uma leitura e interpretação compreendida de forma holística.

A terceira etapa constituiu-se no prognóstico ambiental, por meio das informações observadas propondo a diretrizes para a área de estudo tendo em vista o aprimoramento da interação entre os recursos naturais e a urbanização. Consolida-se por meio de diretrizes que apontam frestas de possibilidades para o desenvolvimento de ações coordenadas; a serem implementadas de acordo com um planejamento que busque vincular a ação antrópica necessária e salva guarde o recurso natural.

\section{RESULTADOS}

\subsection{INDIVIDUALIZAÇÃO DO OBJETO DE ESTUDO}

A Bacia Hidrográfica do Córrego da Onça (BHCO) possui uma extensão de $138.195 \mathrm{~km}^{2}$ e se encontra entre as coordenadas geográficas: $51^{\circ} 48^{\prime} 3^{\prime \prime}$ O e $51^{\circ} 34^{\prime} 41^{\prime \prime} \mathrm{O}, 20^{\circ} 55^{\prime} 53^{\prime \prime}$ S e $20^{\circ} 41^{\prime} 44^{\prime \prime}$ 
S, localizada no município de Três Lagoas, situado na porção leste do Estado do Mato Grosso do Sul-Brasil.

A delimitação evidenciou a presença de grande parte da área urbanizada do município de Três Lagoas/MS e os dados prévios apontam o canal do Córrego da Onça como sendo o principal destino do esgoto e drenagem urbana.

Vale ressaltar que existe uma ausência de certos dados específicos e a descrição dos aspectos físico-ambientais se deu em pequena escala, na qual se insere as bacias hidrográficas em estudo, sendo realizadas algumas observações nos trabalhos de campo por meio de uma escala local/regional.

A seguir a Figura 1 demonstra a situação do município no estado e a localização e delimitação da bacia hidrográfica estudada definida por processamento digital de imagens a partir da imagem Landsat.

Figura 1. Mapa de Localização da Bacia Hidrográfica do Córrego da Onça/MS.

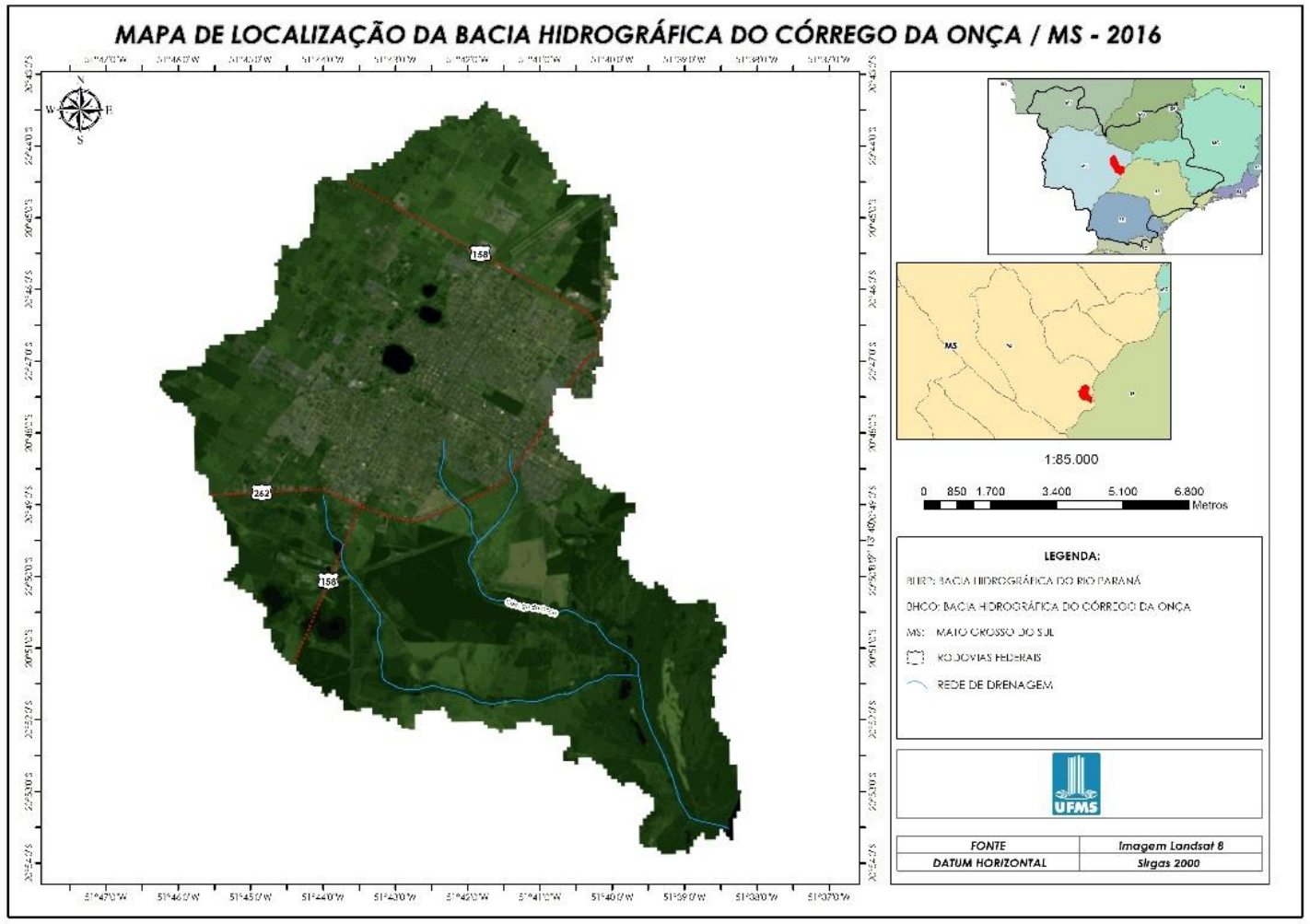

Fonte: PINHO,2018

\subsection{CARACTERIZAÇÃO DAS VARIÁVEIS FÍSICAS}

O levantamento dos dados fisiográficos apontam as seguintes características no contexto da BHCO inserida no território pertencente ao município de Três Lagoas, porção leste do Estado do Mato Grosso do Sul: 


\subsubsection{GEOLOGIA}

Geologicamente, o município de Três Lagoas está localizado na bacia sedimentar do Rio Paraná sobre os depósitos do Grupo Bauru e São Bento, composto pelas Formações Caiuá e Santo Anastácio; destacando-se ainda para o município, a formação Adamantina e os Depósitos Aluvionares. Assim a BHCO pertence à bacia sedimentar do Rio Paraná e pode ser considerada do tipo bacia intracratônica, estando localizada sobre a formação Santo Anastácio do Grupo Bauru, na qual se destacam arenitos cinza-pardo, vermelho-arroxeado ou creme, encontrandose sempre envolto por uma película limonitizada. A granulação é predominantemente fina e esporadicamente média a grosseira, mostrando a presença de um cimento síltico e carbonático, que gradativamente vai aumentando; detectam-se sempre tênues intercalações sílticoargilosas, tornando-se mais espessas para cima; apresentando ainda, Depósitos Aluvionares na foz junto ao Rio Paraná, de acordo com a leitura dos mapas em Fernandes (2013).

\subsubsection{GEOMORFOLOGIA}

A geomorfologia da bacia apresenta segundo Fernandes (2013, p.119): os Divisores Tabulares do Rio Verde contornando grande extensão das Rampas Arenosas dos Planaltos Interiores com a qual se coalesce topograficamente. Passa-se suavemente, sem ruptura de declive, da cota de $500 \mathrm{~m}$ nas Rampas Arenosas dos Planaltos Interiores para a cota dos $400 \mathrm{~m}$ na presente unidade. Inserida na Região Geomorfológica dos Planaltos Areníticos - Basálticos Interiores, dentro da unidade geomorfológica dos Divisores Tabulares dos Rios Verde e Pardo e o Vale do Paraná.

\subsubsection{PEDOLOGIA}

De acordo com a tabela 1 quanto à pedologia, há o predomínio da presença de Latossolo Vermelho-Escuro álico, que passou a ser conhecido apenas por Latossolo Vermelho, conforme a nova classificação brasileira de solos.

Tabela 1. Caracterização da Pedologia

\begin{tabular}{|c|c|c|}
\hline Tipos de Solo & Área km² & $\%$ \\
\hline PVa8 - Argissolo Vermelho Áluminico & 42,18 & 31,84 \\
\hline $\begin{array}{l}\text { Lea9 - Latossolo Vermelho-Escuro álico A moderado } \\
\text { textura média e argilosa relevo plano e suave ondulado }\end{array}$ & 4,84 & 3,65 \\
\hline $\begin{array}{l}\text { Lea22 - Latossolo Vermelho-Escuro álico A moderado, } \\
\text { textura média. }\end{array}$ & 70,55 & 53,27 \\
\hline $\begin{array}{l}\text { AC2 - Área de Solo hidromórfico periodicamente } \\
\text { Inundado }\end{array}$ & 14,89 & 11,24 \\
\hline Total & 132,46 & 100,00 \\
\hline
\end{tabular}

\subsubsection{REGIME CLIMÁTICO}

Segundo a classificação de Köppen, ocorrem dois tipos climáticos no regime hidro climático presente no município de Três Lagoas: o de maior abrangência na área é o AW (clima tropical úmido com estação chuvosa no verão e seca no inverno) e o Ca (clima mesotérmico úmido sem estiagem, em que a temperatura do mês mais quente é superior a $22^{\circ} \mathrm{C}$, apresentando no mês 
mais seco uma precipitação superior a $30 \mathrm{~mm}$ de chuva). A variação mesoclimática do município varia entre úmido e sub-úmido, com índice efetivo de umidade com valores anuais variando de 20 a 40. A precipitação pluviométrica anual varia entre 1500 a $1750 \mathrm{~mm}$ anuais, excedente hídrico anual de 800 a $1200 \mathrm{~mm}$ durante 05 e 06 meses e deficiência hídrica de 350 a $500 \mathrm{~mm}$ durante 04 meses, conforme Fernandes (2013, p. 129).

\subsubsection{COBERTURA VEGETAL}

Quanto aos domínios da vegetação encontra-se na BHCO a predominância de região de Savana (bioma Cerrado) distribuído em vegetação natural arbórea densa entre áreas de cobertura antrópica marcadas pela pastagem e silvicultura. De acordo com a Embrapa, o cerrado denso:

É um subtipo de vegetação predominantemente arbóreo, com cobertura de $50 \%$ a
$70 \%$ e altura média de cinco a oito metros. Representa a forma mais densa e alta de
Cerrado sentido restrito. As camadas de vegetação de arbustos e ervas são menos
adensados, provavelmente devido ao sombreamento resultante da maior cobertura
das árvores. Ocorre principalmente nos solos dos tipos Latossolos Vermelho [...],
Latossolos Vermelho-Amarelo [...] e Cambissolos [...], dentre outros. (EMBRAPA, 2016)

De influência fluvial, em bordas do Rio Paraná há uma porção de áreas de formação pioneiras de vegetação de Floresta Atlântica.

\subsection{CARACTERIZAÇÃO TERRITORIAL}

O município de Três Lagoas/MS, onde está inserida a BHCO, possui uma área de unidade territorial de $10.235,8 \mathrm{~km}^{2}$ e uma população de 101.791 habitantes, de acordo com o IBGE (2010). Para uma melhor avaliação, a BHCO pode ser compartimentada dividindo-se entre: o complexo das lagoas em seu alto curso, Córrego da Onça e Córrego Brasília no médio curso, assim como drenagem intermitente formada por corpo hídrico, que forma a "Lagoa dos Burros" resultante da drenagem da porção oeste da bacia, finalizando no banhado do baixo curso na foz junto ao Rio Paraná.

A figura 2 apresenta recortes do território ilustrando os trechos compartimentados, nos quais podem ser verificadas quais as características mais marcantes em todos os componentes e evidenciar as suas diferenciações: 


\section{Periódica Eletrânica}

Figura 2. llustrações do território nos componentes da BHCO.

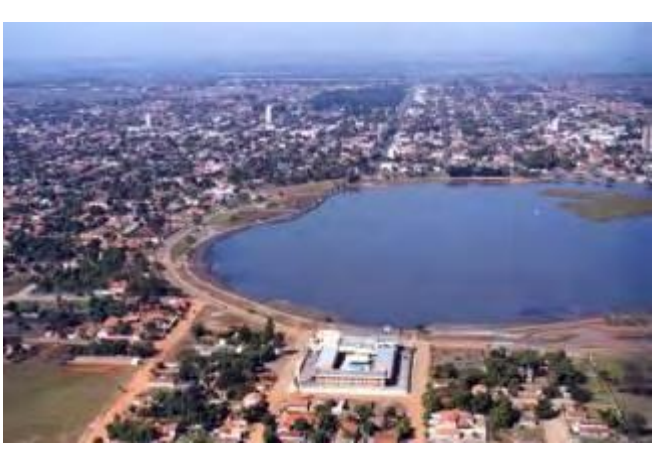

(A) Lagoa Maior no alto curso, urbanizada.

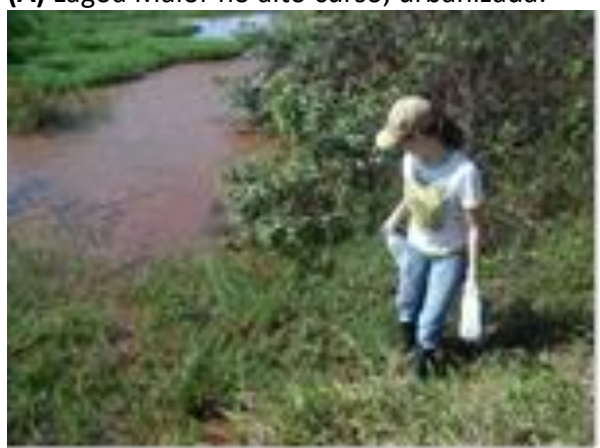

(C) Ressurgência do córrego no médio curso.

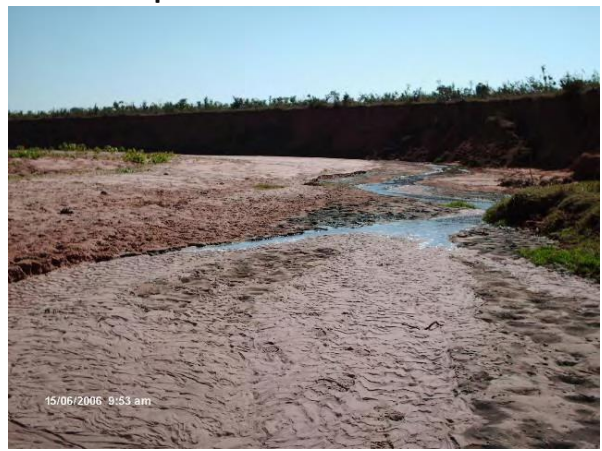

(B) Efluentes oriundos da ETE, médio curso no período seco.

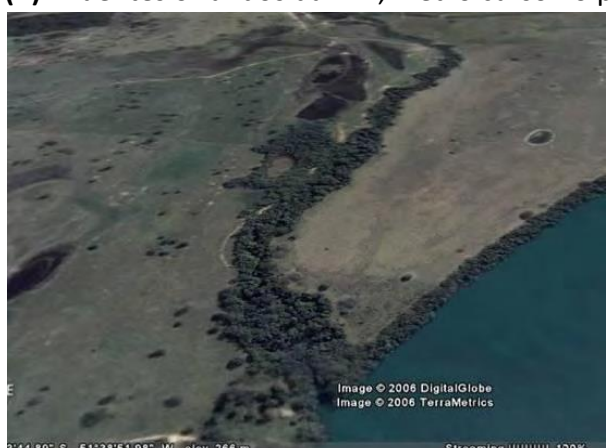

(D) Foz no baixo curso, junto ao Rio Paraná.

Fonte: AMERICO et al, (2015)

O uso e cobertura da terra é o processo pelo qual as atividades antrópicas originam pressões sobre o meio ambiente. A seguir a figura 3 apresenta o Uso e Cobertura da Terra na BHCO em espacialização executada por processamento digital de imagens a partir da imagem Landsat 8. 
Figura 3. Mapa de Uso e Cobertura da Terra na Bacia Hidrográfica do Córrego da Onça/MS

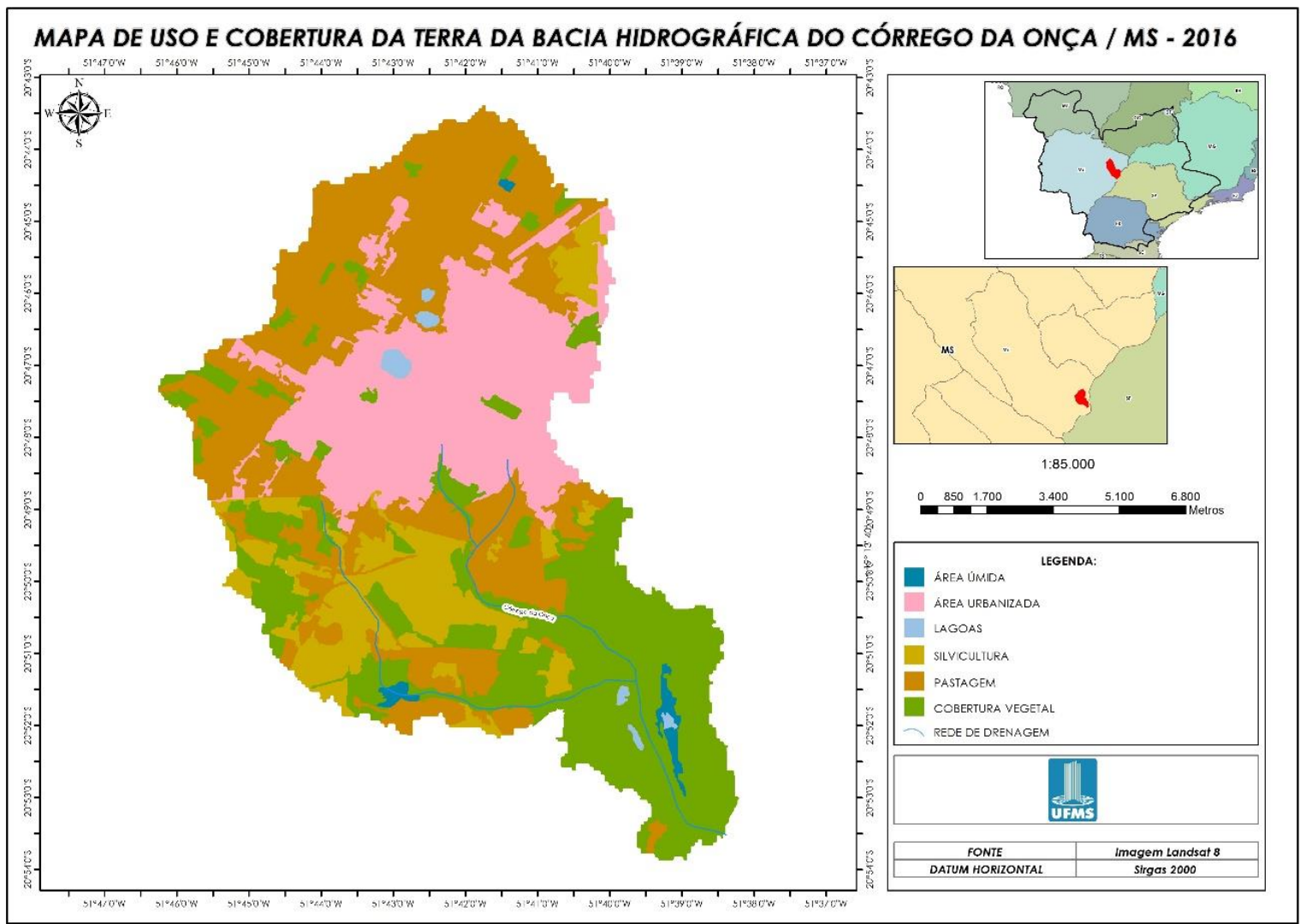

Fonte: PINHO, 2018

A distribuição das classes temáticas caracterizadas no mapa de uso e cobertura da terra pode ser verificada na tabela 2 a seguir.

\begin{tabular}{lcc}
\begin{tabular}{l} 
Tabela 2. Classes Temáticas de Uso e Cobertura da Terra \\
\hline CLASSES TEMÁTICAS
\end{tabular} & $\begin{array}{c}\text { AREAS } \\
\text { (ha) }\end{array}$ & $\begin{array}{c}\text { PERCENTUAL } \\
\text { (\%) }\end{array}$ \\
\hline Área Úmida & 411,81 & 2,98 \\
Área Urbanizada & $3.486,60$ & 25,23 \\
Lagoas & 68,04 & 0,49 \\
Silvicultura & $3.509,19$ & 25,40 \\
Pastagem & $3.129,57$ & 22,65 \\
Cobertura Vegetal & $3.213,03$ & 23,25 \\
Total & $\mathbf{1 3 . 8 1 9 , 5 0}$ & $\mathbf{1 0 0}$ \\
\hline \multicolumn{3}{c}{ Fonte: PINHO, 2018 } \\
\hline
\end{tabular}

De acordo com as informações levantadas pela geração do mapa temático verifica-se que na bacia hidrográfica há uma distribuição de áreas nas quais se destacam as classes de Silvicultura perfazendo a área de 3.509,19 ha (25,40\%); área urbanizada com um percentual de 25,23\% ocupando $3.486,60$ ha e a classe de uso da Pastagem em 3.129,57 ha sendo $22,65 \%$ da totalidade. 
Nota-se a presença da silvicultura alavancada pela plantação da monocultura do eucalipto destinado à produção de papel e celulose em razão da instalação de duas empresas do setor presentes no contexto do município três-lagoense.

No que tange à área de urbanização trata-se da ocupação histórica da cidade de Três Lagoas, que vem sendo expandida a largos passos nos últimos anos impulsionada pelo surgimento de condomínios horizontais de uso residencial bem como de projetos de habitação social voltados às classes de baixa renda e veem ocupando as porções periféricas da mancha urbana.

Pode ainda aferir a ocupação de $23,25 \%$ das terras na BHCO detentoras de cobertura vegetal, dentre as quais podem ser identificadas a presença de áreas úmidas, localizadas no baixo curso do Córrego da Onça, perfazendo uma área de 411,81ha, ou seja, 2,98\% do total da bacia.

Vale destacar a área ocupada pelas lagoas, importante referência no contexto da urbanização de Três Lagoas, que ocupam uma área de 68,04 ha juntamente com alguns outros pontos com presença de lâmina de água, ocupando um percentual de 0,49\%.

Esta caracterização se coaduna com o exposto em Carvalho (2010) apontando que "o interesse aumenta ao se saber que esta é uma área bem segmentada quanto ao seu uso e ocupação da terra, resultando diferentes influências em parcelas específicas da bacia, mas impactando toda sua área." (CARVALHO, 2010, p.26).

\subsection{CARACTERIZAÇÃO DA QUALIDADE DA ÁGUA}

A leitura das condições presentes na Bacia Hidrográfica do Córrego da Onça, em relação às características de suas aguas será realizada a partir de estudos recentes que se debruçaram a entender como as variáveis físico-químicas se apresentam.

O recurso hídrico perpassa o município de Três Lagoas - MS e ao longo do seu percurso sofre interferências da urbanização, da pastagem e da silvicultura, além de receber o efluente da Estação de Tratamento de Esgoto (ETE), situada no médio curso do corpo hídrico. Caracterizase por compor a rede de drenagem e está sujeito à intensa degradação em razão do despejo irregular de esgoto sanitário, bem como do esgotamento oriundo do sistema urbano de drenagem, causador de interferências físicas no solo e em sua vegetação.

A partir destas colocações Américo et al (2015) monitoraram as águas do corpo hídrico entre outubro de 2008 e setembro de 2009, com o intuito de avaliar os dados e compará-los com a Resolução CONAMA 357/05, de 17 de março de 2005.

Pelo fato de não dispor de uma classificação de suas águas, o Córrego da Onça é considerado classe 2, de acordo com o cap. VI, art. 42 da Resolução CONAMA 357/05.

De acordo com as autoras: as maiores temperaturas da água foram registradas no mês de dezembro e oscilaram entre $32^{\circ} \mathrm{C}$ e $37^{\circ} \mathrm{C}$. A menor temperatura deste mês foi encontrada no P6; enquanto a maior ocorreu no $\mathrm{P} 1$ e $\mathrm{P} 2$ que se localizam em área urbanizada. Os menores valores de temperatura ocorreram no mês de junho e variaram de $22,3^{\circ} \mathrm{C}$ a $25^{\circ} \mathrm{C}$.

Quanto ao indicador de acidez, a Resolução CONAMA 357/05 estabelece para as águas doces de classe 2 um índice de pH ente 6 e 9. O P5 teve 75\% de suas amostras com pH menor que 6; no P3 e P6 todas as amostras se enquadraram no padrão estabelecido, enquanto para os dados do 
ponto P4 (Jusante da ETE), nem todas as amostras se enquadraram na legislação apesar dos dados do efluente da ETE em relação a este parâmetro estarem conforme o padrão permitido pela resolução CONAMA 357/05.

Foram coletadas amostras em seis pontos, considerando-se a variação do $\mathrm{pH}$ nos pontos amostrais durante os meses de monitoramento, e os dados de precipitação obtidos, observa-se que os valores de $\mathrm{pH}$ encontrados no córrego apresentaram seus níveis abaixo da neutralidade, sendo que estes coincidem com os meses de maior precipitação. (AMERICO et al, 2015)

Já em relação à concentração de Oxigênio Dissolvido (OD), houve uma variação expressiva entre os pontos ao longo do Córrego da Onça/MS desde $0 \mathrm{mg} \mathrm{L-1}$ no ponto localizado na jusante da ETE (P4) até 12,2 mg L-1 na Lagoa do Meio (P1). A tabela 3 apresenta as médias levantadas no período de Outubro de 2008 a Setembro de 2009.

Tabela 3. Concentração média de OD, em mg L-1
\begin{tabular}{ccccccc}
\multicolumn{6}{c}{ Pontos Amostrais } \\
\hline P1 & P2 & P3 & P4 & P5 & P6 \\
pH & 6,4 & 6,4 & 6,8 & 6,2 & 5,5 & 6,2 \\
\hline
\end{tabular}
Fonte: AMERICO et al (2015, s.p.)

Segundo CONAMA 357/05, a concentração de OD, em qualquer amostra, não pode ser inferior a $5 \mathrm{mg} \mathrm{L-1} \mathrm{em} \mathrm{corpos} \mathrm{d'agua} \mathrm{classificados} \mathrm{como} \mathrm{2.} \mathrm{Das} \mathrm{doze} \mathrm{amostras} \mathrm{coletadas} \mathrm{no} \mathrm{P5,} \mathrm{onze}$ delas apresentaram uma concentração abaixo do padrão estabelecido. Este ponto localizado em afloramentos de água registrou valores menores possivelmente porque há grande quantidade de matéria orgânica de origem vegetal presente na água que durante sua decomposição pode estar consumindo o oxigênio dissolvido no meio.

No P4 apenas três das doze amostras apresentaram concentração de OD igual ou superior a 5 mg L-1. Este fato poderia estar relacionado a não eficiência da ETE na remoção de DBO, no entanto os dados fornecidos pela ETE de Três Lagoas - MS se enquadram no padrão de lançamento de efluente estabelecido pela legislação.

Assim, uma possível explicação tanto para a concentração de OD inferior a $5 \mathrm{mg}$ L-1 quanto para o pH não adequado é a vazão quase nula (principalmente nos meses de estiagem) do canal do córrego onde o efluente é lançado que não permite uma diluição adequada do efluente.

Destaca-se também, a partir dos estudos de AMÉRICO (2010), no tocante aos aspectos químicos no Córrego da Onça a presença de compostos farmacológicos em índices preocupantes, tais como: atenolol (com a menor diferença significativa) e naproxeno (com o maior desvio padrão); sendo o diclofenaco o composto mais presente em vários pontos ao longo do curso hídrico. Esta identificação acende uma luz de alerta em razão dos riscos associados às saúdes humana e ambiental, uma vez que compromete a biota aquática e o possível contato humano, principalmente em épocas de estiagens, nas quais os níveis de diluição aquosa no corpo hídrico são menores e estão mais evidentes a jusante da Estação de Tratamento de Esgoto Planalto. 


\section{DISCUSSÃO}

Em um diagnóstico preliminar e partindo de uma análise holística (sistêmica) podemos considerar a BHCO como um subsistema pertencente a um sistema maior que é o do Rio Paraná, sendo a compartimentação em alto-médio-baixo cursos, definidora dos componentes desta leitura.

Nesta perspectiva a instabilidade originada do regime fluvial é agravada pelo solapamento nas margens e alagamento das planícies. A descontinuidade da vegetação natural altera a estabilidade ambiental.

Em razão dos tipos diversos de ocupação acumulando: ora as altas taxas de impermeabilidade, ora o uso desordenado; e considerando ainda a baixa potencialidade rural das terras, que leva a busca pela valorização por meio da expansão urbana e ainda a descaracterização da fitoecologia pela ocupação, verifica-se a tendência de desestabilidade da ecodinâmica.

O fato de a urbanização assentar-se em torno da cota $325 \mathrm{~m}$, a cerca de $70 \mathrm{~m}$ acima do Rio Paraná, constitui um tecido urbano em área estritamente plana de maneira a gerar graves dificuldades e problemas no tocante a drenagem de águas pluviais. Tendo o Córrego da Onça se tornado o principal canal de drenagem urbana desde o alto curso, no qual estão presentes as lagoas, até passar pelo médio curso: onde recebe o esgotamento dos resíduos urbanos até ir apresentar uma recuperação de seu estado mais natural já próximo a foz do Rio Paraná.

No caso das lagoas, situadas no alto curso, temos duas situações que merecem atenção:

- em torno da Lagoa Maior (cartão postal e principal área de contato com a natureza na cidade) a urbanização se apresenta consolidada e vivencia frequentes alagamentos em dias de chuvas, em razão do alto grau de impermeabilização e a falta de sistema complementar de drenagem. Detecta-se também o alto índice de detritos que são levados do entorno para dentro da lagoa, alterando seu nível de profundidade ao longo dos anos;

- já na área das demais lagoas (conhecidas como: segunda e menor), a ocupação segue os padrões sem ordenamento racionalizado, tendendo a agravar o estado do conjunto, uma vez que há o interligamento das lagoas por meio de dutos.

Torna-se de grande relevância buscar meios de tratar os problemas nas lagoas, fato este que se justifica pelo valor ambiental e simbólico que as mesmas possuem para o contexto da cidade de Três Lagoas/MS.

No que tange ao médio curso, temos boa parte do Córrego da Onça canalizado, em meio urbano consolidado com a presença histórica de população. Identifica-se que o princípio da canalização esta a partir da Lagoa Maior e segue subterraneamente até ressurgir nas proximidades de um bairro periférico com alta taxa de ocupação. Neste caso temos a caracterização mais latente dos conflitos que envolvem grupos sociais, o meio ambiente, a municipalidade e o Direito, devendo ser estabelecido como serão tratadas as questões referentes às exigências legais de proteção ao recurso hídrico e ainda atender as necessidades de uma população, que em sua maioria, se enquadra em índices de baixa renda. 
Nos dois casos acima, tanto no alto curso, quanto no médio curso: a consideração dos dados de caracterização da qualidade das águas; apontando as irregularidades dos aspectos físicoquímicos e a presença de compostos farmacológicos em índices preocupantes, reforçam a necessidade de atenção e intervenção racionalizada e sistemática a fim de combater os riscos às saúdes humana e ambiental.

Observa-se no baixo curso a expressiva cobertura vegetal e a presença da mata ciliar em algumas zonas de APP's favorecendo a recuperação da qualidade das aguas; e ainda, se for considerado que a falta de vegetação pode provocar o aceleramento dos transportes de sedimentos do entorno para o canal do recurso hídrico; pode-se salientar a relevância deste contexto para o conjunto ambiental: planície-várzea-córrego e por consequência para a biodiversidade da flora e da fauna.

Torna-se importante relatar que o crescente cultivo do eucalipto gera diversas discussões em razão da divergência de posições sobre os efeitos da implantação de uma monocultura reforçada ainda pela falta de dados sobre seus impactos sobre os solos, regime hídrico e biodiversidade, reforçando a necessidade de estudos específicos.

Neste diagnostico preliminar pode-se constatar a diversificação da problemática que envolve a interação de recursos hídricos e a urbanização. Trata-se principalmente de evidenciar os conflitos que podem existir quando se tem um curso d'água permeando o tecido urbano e uma área rural de uso e características variadas.

Porém, mais do que procurar pensar as diversas partes isoladamente, torna-se necessário realizar uma leitura que permita a visualização do contexto. Neste sentido, mesmo partindo de uma análise compartimentada da BHCO devem ser buscadas proposições que integrem as partes de modo a se estabelecer uma nova realidade possível.

Não se trata de pensar uma ação universalizante, uma vez que as ações devem ser programadas de acordo com as especificidades de cada problema, porém reforça-se a necessidade da leitura do conjunto, que poderá proporcionar frestas de novas possibilidades sintático semânticas, ou seja: possíveis percursos de ação a fim de abrir o debate público desencadeador de iniciativas de urbanismo prático.

\section{CONCLUSÃO}

O recorte da bacia hidrográfica como área de estudo mostrou a integridade de uma porção do território em relação aos aspectos fisiográficos estabelecendo um sistema de análise bem delimitado no espaço. Assim a análise socioambiental integrada (sistêmica) do uso e cobertura da terra, com o apoio do geoprocessamento, aliada à análise da qualidade das águas do corpo hídrico confirmou a histórica interação conflituosa entre recurso natural e urbanização.

Foi possível discutir como as características antrópicas e naturais, quando identificadas e relacionadas, podem ser a base para a obtenção de uma "fotografia" da realidade que se constitui no ponto de partida para a implementação de ações voltadas ao planejamento ambiental. 
Como um diagnóstico preliminar verificou se a possibilidade de compartimentação em cursos na $\mathrm{BHCO}$, apresentando uma leitura que evidencia a dimensão das problemáticas e pode direcionar um urbanismo pratico de modo a atender as especificidades de cada componente. No entanto cabe ressaltar que a visão integrada da BHCO mostra que as soluções que busquem alinhar as problemáticas devem ser viáveis no que tange a organização dos setores públicos e privados atuantes no contexto do território bem como permitir a participação da sociedade civil organizada.

Destaca-se que esta pesquisa não deve considerada como definitiva em relação às temáticas abordadas; de modo que este trabalho deva ser visto como uma ferramenta para auxiliar futuros estudos a fim de complementar ou realizar novas considerações sobre as transformações ocorridas na Bacia Hidrográfica do Córrego da Onça; lendo este material como uma possibilidade de criar estratégias de ações urbanísticas sustentáveis em busca de um uso, manejo e ocupação do território mais consciente face aos seus reflexos nos recursos naturais.

\section{AGRADECIMENTOS}

O presente trabalho foi realizado com apoio da Universidade Federal de Mato Grosso do Sul UFMS/MEC - Brasil

\section{REFERÊNCIAS BIBLIOGRÁFCAS}

AMERICO,J.H.P. Ocorrência de Compostos Farmacológicos no Córrego da Onça, município de Três Lagoas - MS. Dissertação (Mestrado). UNESP 2010.

AMERICO,J.H.P; MANOEL, L.O.; TORRES, N.H. Avaliação de Parâmetros Físico-Químicos da Água do Córrego da Onça, Três Lagoas - MS. Periódico Eletrônico: XI Fórum Ambiental da Alta Paulista, v. 11, n. 6, 2015, pp. 250-257

BRASIL. Ministério do Meio Ambiente. Resolução CONAMA n³57 de 17 de marco de 2005. Alterada pela Resolução 410/2009 e pela 430/2011. Dispõe sobre a classificação dos corpos de água e diretrizes ambientais para o seu enquadramento, bem como estabelece as condições e padrões de lançamento de efluentes, e dá outras providências. Publicada no DOU no 053, de 18/03/2005, págs. 58-63 Disponível em:

<http:www.mma.gov.br/port/conama> Acesso: 25/11/2016.

Ministério do Meio Ambiente. Software livre para Geoprocessamento. Disponível em <http://www.mma.gov.br/governanca-ambiental/geoprocessamento/item/893> Acesso em 13/04/2017

CARVAlho, A. G. B. M. de. Proposição de Geoindicadores para Caracterização da Degradação do Meio Físico na Bacia Hidrográfica do Córrego da Onça, Três Lagoas (MS). 2010. 1302 f. Dissertação (Mestrado em Engenharia Civil). Universidade Estadual Paulista "Júlio de Mesquita Filho" Faculdade de Engenharia (Campus de Ilha Solteira) UNESP, Ilha Solteira, 2010.

CARVALHO, A. G. B. M; GONZAGA, M. L; CARVALHO, F. L. B. M; LOLLO, J. A. Identificação das degradações ambientais e proposição de alternativas de uso e recuperação de bacias hidrográficas: a bacia hidrográfica do córrego da onça (Três Lagoas-MS-Brasil). - UNESP, Rio Claro/SP, 2010.

CHRISTOFOLETTI, A. Modelagem de Sistemas Ambientais. São Paulo: Edgard Blücher, 1999.236p.

DPI - INPE. Divisão de Processamento de Imagens - Instituto de Pesquisas Espaciais. Tutorial de Geoprocessamento. Classificação de Imagens, 2006. Disponível em: <http://www.dpi.inpe.br/SPRING ${ }^{\bullet}$ 5.4.2/portugues/index.html> Acesso em 08 de março de 2017. 
Imagem LANDSAT 8 OLI TIRS e PAN, Órbita 223, ponto 073 - 05 de Outubro de 2016. Departamento de Geração de Imagens. Disponível em: <http://www.dgi.inpe.br/siteDgi/portugues/satelites.php>. Acesso em 06 de novembro de 2016.

EMBRAPA - Empresa Brasileira de Pesquisa Agropecuária. Agência de Informação Embrapa. Bioma Cerrado. Disponível em:<http://www.agencia.cnptia.embrapa.br/Agencia16/AG01/arvore/AG01_41_911200585233.html>. Acesso em 08 de setembro de 2016.

. LANDSAT - Land Remote Sensing Satellite. Disponível em

<https://www.cnpm.embrapa.br/projetos/sat/conteudo/missao_Landsat.html>. Acesso em 12 de maio de 2017.

FERNANDES, A. L. V. As Transformações da Paisagem nas Bacias Hidrográficas Influenciadas pelo Complexo Celulósico: Três Lagoas e Selvíria, MS.2013. 294f. Dissertação (Mestrado em Geografia). UFMS, Três Lagoas-MS, 2013.

FRANÇA, J. S.; SANTOS, T. R.; GOMES, W. M. Degradação socioambiental do Córrego da Onça, Três Lagoas/MS. Volume 8, nº 12 - UFMS, Três Lagoas, 2012.

FRANCO, M. A. R. Planejamento ambiental para a cidade sustentável. São Paulo: Annablume: FAPESP, 2003.

GONZAGA, M. Dinâmica ambiental da bacia hidrográfica do córrego da onça (Três Lagoas/MS): o uso do solo e a legislação pertinente 2012. 123 f. Dissertação (Mestrado em Engenharia Civil). Universidade Estadual Paulista "Júlio de Mesquita Filho" Faculdade de Engenharia (Campus de Ilha Solteira) UNESP, Ilha Solteira, 2012.

IBGE - Instituto Brasileiro de Geografia e Estatística. Manual Técnico de Uso da Terra. 3ạ Edição. Disponível em: $<$ http://www.ibge.gov.br>. Acesso em: 06 de setembro. 2016. setembro. 2016

Manual Técnico de Pedologia. 2a Edição. Disponível em: <http://www.ibge.gov.br>. Acesso em: 06 de

Panorama das cidades brasileiras/ Três Lagoas-MS, 2015. Disponível em

$<$ https://cidades.ibge.gov.br/v4/brasil/ms/tres-lagoas/panorama> Acesso em 13/06/2017.

LORENZ-SILVA, J.L. O Espongilito de Três Lagoas, MS. Registro e Caracterização com ênfase em Micropaleontologia. Tese de Doutorado em Geologia. UNISINOS São Leopoldo, RS.: 2003.170 p.

MELLO, A. L. da S. Análise das características ambientais com geoprocessamento na Bacia Hidrográfica do Córrego da Onça em Três Lagoas/MS. Dissertação (Mestrado em Geografia). UFMS, Três Lagoas-MS, 2016.

MIRANDOLA, P. H. Análise geo-ambiental multitemporal para fins de planejamento ambiental: um exemplo aplicado à bacia hidrográfica do Rio Cabaçal Mato Grosso - Brasil. 2006, 317 f. Tese (Doutorado em Geografia) Universidade Federal do Rio de Janeiro, 2006.

A Trajetória da Tecnologia de Sistemas de Informação Geográfica (SIG) na Pesquisa Geográfica. Revista Eletrônica da Associação dos Geógrafos Brasileiros - Seção de Três Lagoas/MS. Nov. 2004, 21-37p.

PEREIRA, E. M. (org.). Planejamento Urbano no Brasil. Conceitos, diálogos e praticas. Chapecó: Argos, 2008. 311p.

PINHO, Rodrigo Guimarães. INDICAÇÃo DE DIRETRIZES DE PLANEJAMENTO POR MEIO DA ANALISE SOCIOAMBIENTAL INTEGRADA (2006- 2016) DA BACIA HIDROGRÁFICA DO CÓRREGO DA ONÇA -TRÊS LAGOAS (MS). 2018.135 f. Dissertação (Mestrado em Geografia) - Universidade Federal do mato Grosso do Sul, Três Lagoas/MS, 2018.

PINTO, A. L; SILVA, J.L.L; FERREIRA, A. G; BASSO, P. M. Subsidio geológico/ Geomorfológico ao ordenamento do uso, ocupação e manejo do solo, visando à redução da perda do solo e a recuperação da qualidade das águas superficiais da Bacia do Córrego Bom Jardim, Brasilândia/MS. Relatório Parcial FUNDECT/MS. UFMS. Três Lagoas, 2009: 42p.

ROSA, R. Metodologia para Zoneamento de Bacias Hidrográficas Utilizando Produtos de Sensoriamento Remoto e Integrados por Sistema de Informação Geográfica. Anais do VIII Simpósio Brasileiro de Sensoriamento Remoto, Salvador - Brasil. INPE, 1996. p. 363-386. 
RUFINO, I. A. SIG e Modelagem de Dados. Disponível em: <

http://www.hidro.ufcg.edu.br/twiki/pub/IanaRufino/CursosLatoSensu/SIGeMod_Illa.ppt >. Acesso em 15 de Abr. de 2010.

SANTOS, R. F. dos, Planejamento Ambiental: teorias e prática. São Paulo: Oficina de Textos, 2004.

SEPLAN/MS - Secretaria de Planejamento e Coordenação Geral de Mato Grosso do Sul. Atlas Multirreferencial do Estado de Mato Grosso do Sul. Conv. Fundação IBGE (Solos, Vegetação, Geologia, Geomorfologia e Clima). Campo Grande - MS, 1990.

SOUZA, M. A. de. Diagnóstico das alterações temporais no uso e ocupação do solo da sub-bacia do Ribeirão Campo Triste, Três Lagoas MS, no período de 1974 a 2007. 2010. 123 f. Dissertação (Mestrado em Geografia). UFMS, Três Lagoas-MS, 2010.

SPRING: Integrating remote sensingand GIS by object-oriented data modelling" Camara G, Souza RCM, FreitasUM, Garrido J Computers \& Graphics, 20: (3) 395-403, May-Jun 1996. 